\title{
Three new species of the myrmecophilous genus Doryloxenus from China (Coleoptera, Staphylinidae, Aleocharinae)
}

\author{
Xiao-Bin Song', Li-Zhen $\mathrm{Li}^{\prime}$ \\ I Department of Biology, College of Life and Environmental Sciences, Shanghai Normal University, 100 Gui- \\ lin Road, Xuhui District, Shanghai 200234, P. R. China \\ Corresponding author: Li-Zhen Li (lizhenli@shnu.edu.cn)
}

Academic editor:J. Klimaszewski| Received 15September2014|Accepted31 October 2014| Published21 November 2014

http://zoobank.org/10B0FA86-AB6F-40BA-8F19-1BFB8A6FA777

Citation: Song X-B, Li L-Z (2014) Three new species of the myrmecophilous genus Doryloxenus from China (Coleoptera, Staphylinidae, Aleocharinae). ZooKeys 456: 75-83. doi: 10.3897/zookeys.456.8584

\begin{abstract}
Three new species of the pygostenine genus Doryloxenus Wasmann, viz., D. aenictophilus sp. n. (from Zhejiang), D. tangliangi sp. n. (from Zhejiang), and D. songzhigaoi sp. n. (from Yunnan), are described, illustrated and distinguished from the Asian congeners. An identification key to the Chinese species is given.
\end{abstract}

\section{Keywords}

Pygostenini, Doryloxenus, myrmecophilous, army ant, new species, China

\section{Introduction}

The myrmecophilous genus Doryloxenus Wasmann currently contains 36 species worldwide (Jacobson and Kistner 1975; Jacobson 1980; Naomi 1996; Pace 1998; Kistner et al. 2003; Assing 2009), among which three are known from China: D. hongkongensis Pace (Hongkong), D. rougemonti Pace (Hongkong), and D. yunnanus Assing (Yunnan). Members of Doryloxenus are commonly found in association with the army ant genus Dorylus, but symbiotic hosts of all Chinese Doryloxenus remain unknown.

In 2013, the senior author and his colleagues surveyed the myrmecophilous and termitophilous staphylinidae at Longwangshan Natural Reserve, Zhejiang (Fig. 4A) and 
Zizhi Village, Yunnan (Fig. 4C), and collected a series of aleocharine beetles from the colonies of army ant Aenictus sp. and Dorylus orientalis. A closer examination of this material revealed three new species of the genus Doryloxenus, which are described herein.

\section{Material and methods}

Holotypes and most of the paratypes are deposited in the Insect Collection of the Shanghai Normal University, Shanghai, China (SNUC), and some of paratypes are deposited in the Kyushu University Museum, Fukuoka, Japan (KUM).

Specimens were killed with ethyl acetate and preserved in 75\% ethanol before dissection; photos of habitus were taken by a Canon EOS 7D with an MP-E $65 \mathrm{~mm}$ macro photo lens; photos of characteristic pattern were taken by a Canon G9 Camera mounted on an Olympus CX31 microscope.

The following abbreviations are applied in the text: $\mathbf{B L}$ - body length, from the anterior margin of the head to the posterior margin of the abdominal tergite VIII; FBL - forebody length, from the clypeal anterior margin to the posterior margin of elytra; HL - head length, from the clypeal anterior margin to the occipital constriction; PL - length of the pronotum along the midline; HW - width of the head across the eyes; PW - maximum width of the pronotum.

\section{Taxonomy}

\section{Doryloxenus Wasmann}

Doryloxenus Wasmann, 1898: 101 (original description, type species: Doryloxenus cornutus Wasmann, 1898); Jacobson and Kistner 1975: 299 (key, diagnosis).

Remarks. The genus is most similar to Odontoxenus Kistner in general appearance. It can be easily separated from Odontoxenus by the eyes having no part of their surface on the anterior margin of the head, the quadrate mesocoxal cavity, and the shorter mesosternum (Jacobson and Kistner 1975). Doryloxenus is also similar to Pygoplanus Kistner by the limuloid shape, but can be distinguished from it by the different shapes of the mandibles and labrum, the maxillary palpus distinctly longer than the setulate galea (Kistner et al. 2003).

\section{Doryloxenus aenictophilus sp. $\mathbf{n}$.} http://zoobank.org/0499D286-4426-4DF2-A379-02BC548E288F Fig. 1

Type material. Holotype: China: $\widehat{\delta}$, labeled 'CHINA: Zhejiang Province, Huzhou City, Anji County (安吉县), Longwangshan (龙王山), alt. $1330 \mathrm{~m}, 30^{\circ} 24^{\prime} 15.53 " \mathrm{~N}$, 


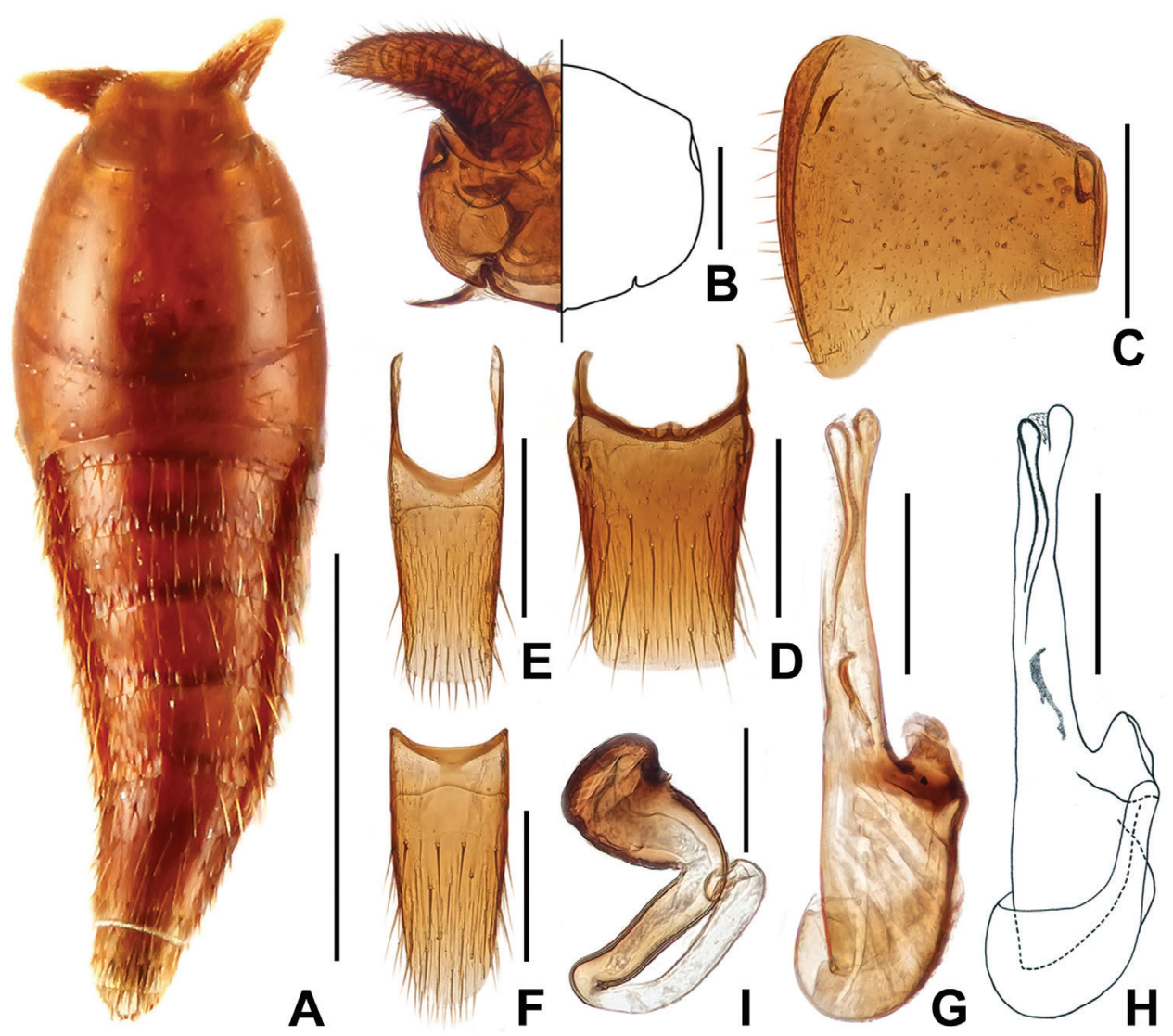

Figure I. Doryloxenus aenictophilus sp. n. A habitus B head C Elytron D tergite VII E tergite VIII $\mathbf{F}$ sternite VIII $\mathbf{G}$ median lobe of aedeagus, in lateral view $\mathbf{H}$ ditto $\mathbf{I}$ spermatheca. Scales $(\mathrm{mm}): \mathbf{A}=0.5$; $\mathbf{B}, \mathbf{G}, \mathbf{H}=0.1 ; \mathbf{C}, \mathbf{F}=0.2 ; \mathbf{I}=0.05$.

$119^{\circ} 26^{\prime} 36.81 " E, 14-V-2013$, X.-B. Song leg., from a colony of Aenictus sp. / HOLOTYPE [red], Doryloxenus aenictophilus sp. n., Song \& Li det. 2014, SNUC'. Paratype: China: 1 ก 19 , 8 sex?, same data as holotype, bearing the following label: 'PARATYPE [yellow], Doryloxenus aenictophilus sp. n., Song \& Li det. 2014'. (SNUC, KUM).

Comparative notes. Doryloxenus aenictophilus is most similar to D. tangliangi described below by the forebody sparsely covered with yellow setae and the macrochaetotaxy of tergites II-V: 6, 4, 4, 4, 4. It differs from $D$. tangliangi by the smaller eyes, the shorter elytra and the reduced hind wings. The new species is also similar to the unique blind and wingless species $D$. coecus Kistner by the light color and the short elytra, but can be easily distinguished from it by the presence of small eyes, the different macrochaetotaxy of abdominal tergites II-VIII.

Description. Body (Fig. 1A) smooth, glossy. Coloration: Light reddish-brown overall.

Head shaped as in Fig. 1B, sparsely covered with yellow setae; eyes small. Pronotum (Fig. 1A) wider than long, about 1.44 times as wide as long; disc sparsely covered 
with yellow setae. Elytra (Fig. 1A, C) short, wider than long, about 3.72 times as wide as long; disc sparsely covered with yellow setae, with a row of setae on lateral margins. Hind wings reduced. Abdomen wedge-shaped; posterior margins of tergite II-VI with a row of very long yellowish setae; abdominal tergite VII (Fig. 1D) truncate at apex, with 2 pairs of macrochaetae at the anterior 1/3; tergite VIII (Fig. 1E) slightly truncate at apex, with 1 pair of lateral macrochaetae; sternite VIII shaped as in Fig. 1F. Macrochaetotaxy of abdominal tergites II-VIII: 6, 4, 4, 4, 4, 4, 2.

Male. Median lobe of aedeagus shaped as in Fig. 1G-H.

Female. Spermatheca with apical part strongly swollen, shaped as in Fig. 1I.

Measurements. BL: 1.48-1.61; FBL: 0.64-0.68; PL: 0.33-0.35; PW: 0.48-0.51; PW/PL: 1.42-1.45; HW/PW: 0.51-0.56.

Distribution. East China: Zhejiang.

Symbiotic host. Aenictis sp. (Fig. 5A-B). According to the key provided by Jaitrong and Yamane (2011), the host ant should belong to the A. ceylonicus group. This is the first record of a Doryloxenus associated with Aenictus ant together with the next new species.

Biological notes. Eleven Doryloxenus aenictophilus were sifted together with a large series of $D$. tangliangi from the colony of Aenictus sp. nesting under a rock. One individual was observed riding on the head of a worker ant.

Etymology. The specific name is a combination of 'Aenictus', generic name of the ant host, and the Greek stem 'philos', meaning 'to be fond of.

\section{Doryloxenus tangliangi sp. $\mathrm{n}$.} http://zoobank.org/BBD8E915-9ED8-4361-B3E1-0F500BB2BAD2

Fig. 2

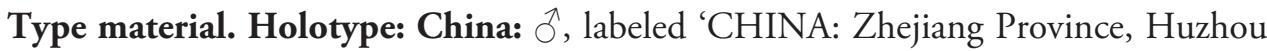
City, Anji County (安吉县), Longwangshan (龙王山), alt. $1330 \mathrm{~m}, 30^{\circ} 24^{\prime} 15.53$ "N, $119^{\circ} 26^{\prime} 36.81 " E, 14-V-2013$, X.-B. Song leg., from a colony of Aenictus sp. / HOLOTYPE [red], Doryloxenus tangliangi sp. n., Song \& Li det. 2014, SNUC'. Paratype: China: $5 \partial^{\lambda}, 3+$, 102sex?, same data as holotype, bearing the following label: 'PARATYPE [yellow], Doryloxenus tangliangi sp. n., Song \& Li det. 2014'. (SNUC, KUM).

Comparative notes. Doryloxenus tangliangi is most similar to D. aenictophilus described above by the forebody sparsely covered with yellow setae and the macrochaetotaxy of tergites II-V: 6, 4, 4, 4, 4. It differs from D. aenictophilus by the larger eyes, the relatively long elytra, as well as the different shapes of the aedeagus and spermatheca.

Description. Body (Fig. 2A) smooth, glossy. Coloration: Light reddish-yellow overall.

Head shaped as in Fig. 2B, sparsely covered with long yellowish setae; eyes large. Pronotum (Fig. 2A) wider than long, about 1.44 times as wide as long; disc sparsely covered with long yellowish setae. Elytra (Fig. 2A, C) about 2.73 times as wide as long; disc sparsely covered with long yellowish setae, with a row of setae on lateral margins. Abdomen wedge-shaped; posterior margins of tergite II-VI with a row of very long 


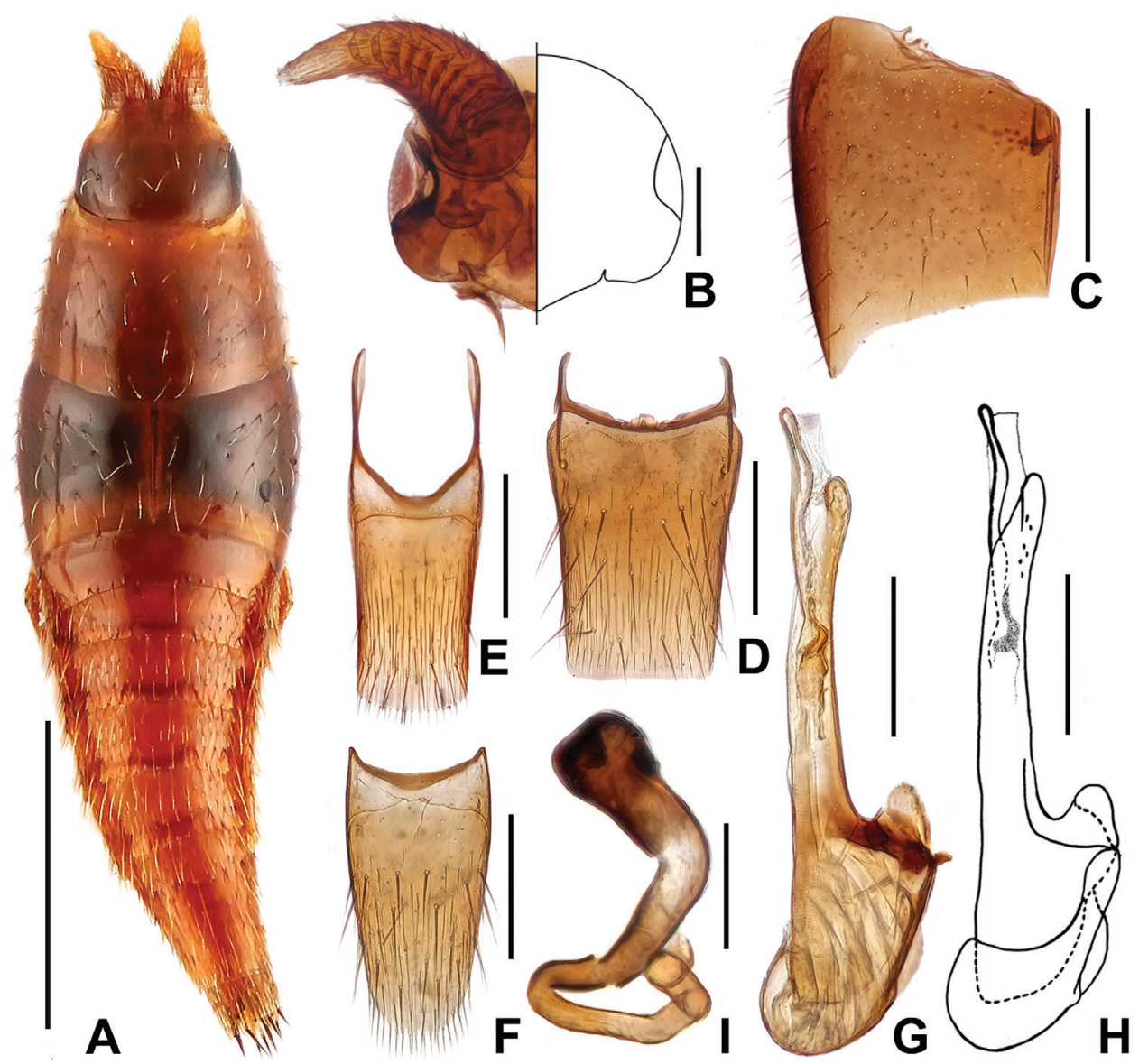

Figure 2. Doryloxenus tangliangi sp. n. A habitus B head C Elytron D tergite VII E tergite VIII F sternite VIII $\mathbf{G}$ median lobe of aedeagus, in lateral view $\mathbf{H}$ ditto $\mathbf{I}$ spermatheca. Scales $(\mathrm{mm}): \mathbf{A}=0.5 ; \mathbf{B}, \mathbf{G}, \mathbf{H}=$ $0.1 ; \mathbf{C}, \mathbf{F}=0.2 ; \mathbf{I}=0.05$.

yellowish setae; abdominal tergite VII (Fig. 2D) truncate at apex, with 2 pairs of macrochaetae at the anterior $1 / 3$ and 3 pairs near apex ; tergite VIII (Fig. 2E) slightly truncate at apex, with 1 pair of lateral macrochaetae and 2 pairs near apex; sternite VIII shaped as in Fig. 2F. Macrochaetotaxy of abdominal tergites II-VIII: 6, 4, 4, 4, 4, 10, 6.

Male. Median lobe of aedeagus shaped as in Fig. 2G-H.

Female. Spermatheca with apical part strongly swollen, shaped as in Fig. 2I.

Measurements. BL: 1.70-1.93; FBL: 0.77-0.86; PL: 0.34-0.37; PW: 0.51-0.52; PW/PL: 1.38-1.53; HW/PW: 0.63-0.67.

Distribution. East China: Zhejiang.

Symbiotic host. Aenictus sp. (Fig. 5A-B).

Biological notes. Most of the specimens were sifted from a colony of Aenictus ant, at least four individuals were observed riding on the abdomen of worker ants (Fig. 4B).

Etymology. Dedicated to Dr. Liang Tang, who found the colony of the host ants. 


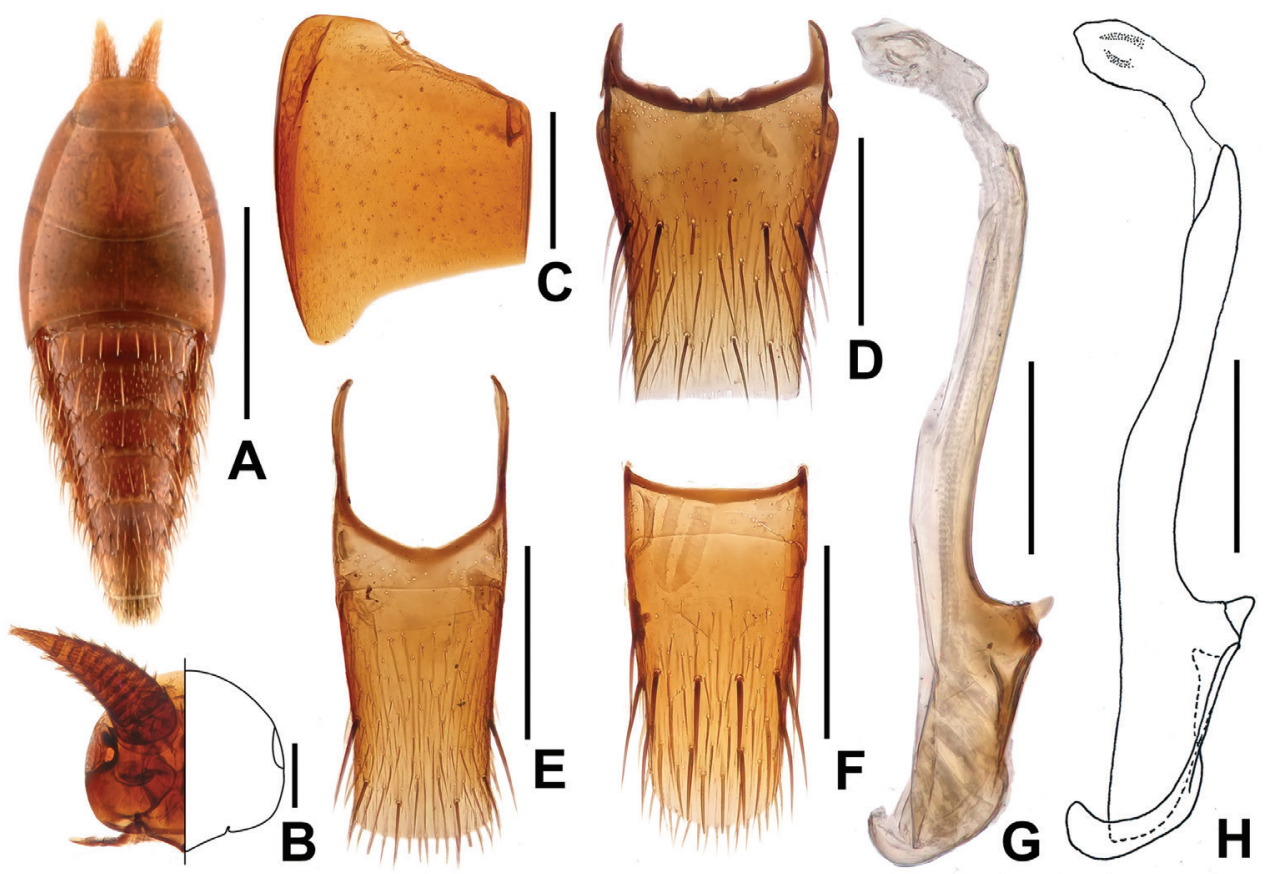

Figure 3. Doryloxenus songzhigaoi sp. n. A habitus B head C Elytron D tergite VII E tergite VIII F sternite VIII $\mathbf{G}$ median lobe of aedeagus, in lateral view $\mathbf{H}$ ditto. Scales $(\mathrm{mm}): \mathbf{A}=0.5 ; \mathbf{B}, \mathbf{G}, \mathbf{H}=0.1 ; \mathbf{C}, \mathbf{F}=0.2$.

\section{Doryloxenus songzhigaoi sp. $\mathrm{n}$.}

http://zoobank.org/CFB4FD49-5CA3-4DAD-97F5-BB77C22FA480

Fig. 3

Type material. Holotype: China: ${ }^{\lambda}$, labeled 'CHINA: Yunnan, Tengchong City, Mingguang Town (明光乡), Zizhi Vill. (自治村), Donghe (东河), alt. 2400m, $25^{\circ} 42^{\prime} 57^{\prime \prime N}, 98^{\circ} 35^{\prime} 42^{\prime \prime E}, 30-I V-2013$, X.-B. Song leg., from a colony of Dorylus orientalis / HOLOTYPE [red], Doryloxenus songzhigaoi sp. n., Song \& Li det. 2014, SNUC'. Paratype: China: $3 \hat{\partial}$, same data as holotype, bearing the following label: 'PARATYPE [yellow], Doryloxenus songzhigaoi sp. n., Song \& Li det. 2014'. (SNUC).

Comparative notes. Doryloxenus songzhigao $i$ is most similar to D. nepalensis $\mathrm{Naomi}$ in general appearance, but can be easily separated from it by the different macrochaetotaxy of abdominal tergites II-VIII. The new species can be distinguished from the other congener known from the Gaoligong Shan, D. yunnanus, by the slender tergite VIII, rounded apex of sternite VIII, and different shape of the aedeagal median lobe.

Description. Body (Figs 3A, 4D) smooth, glabrous. Coloration: Light reddishyellow overall.

Forebody shaped as in Fig. 3A, with sparse punctation. Head shaped as in Fig. 3B. Pronotum (Fig. 3A) about 1.71 times as wide as long. Elytra (Fig. 3A, C) about 2.55 times as wide as long. Abdomen wedge-shaped; posterior margins of tergite II-VI 


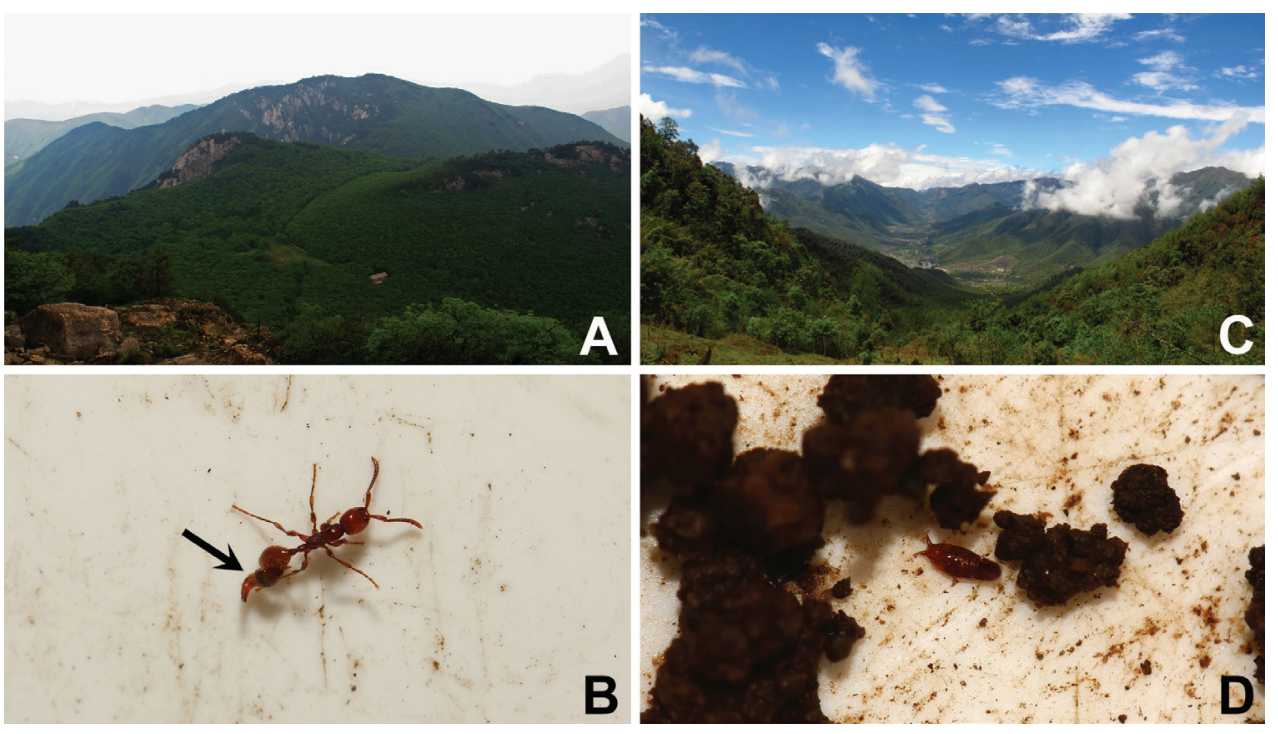

Figure 4. A Longwangshan Natural Reserve B D. tangliangi riding on the abdomen of an Aenictus ant C Type locality of $D$. songzhigaoi (Donghe, Zizhi Village) D D. songzhigaoi, habitus.

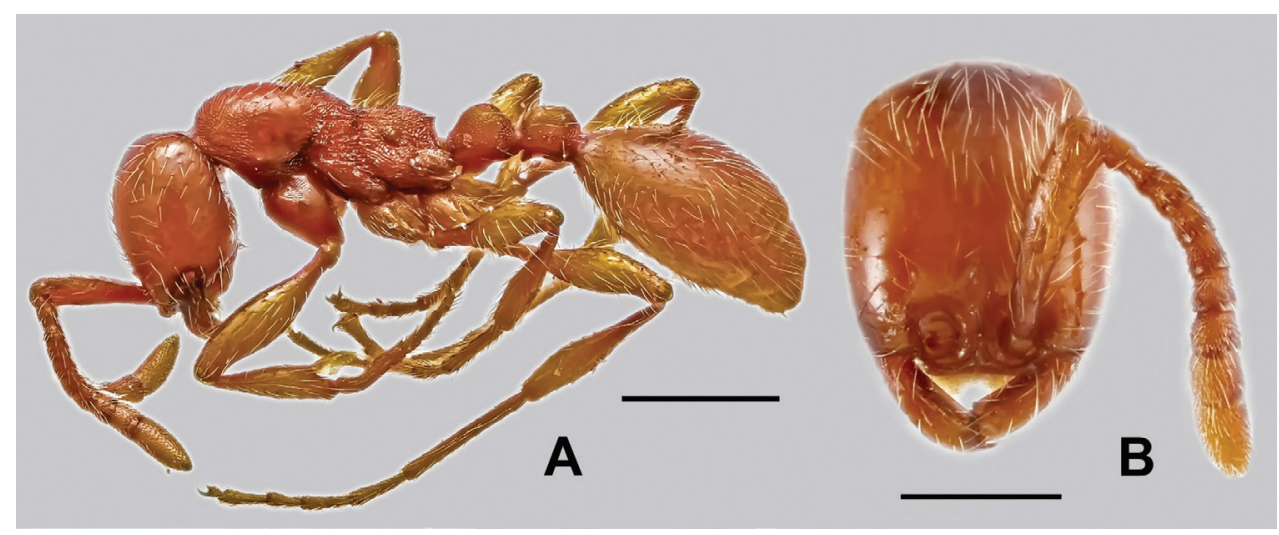

Figure 5. Host ant of $D$. aenictophilus and $D$. tangliangi A Aenictus sp., in lateral view B ditto, head in full face view. Scales $(\mathrm{mm})$ : $\mathbf{A}=0.5 ; \mathbf{B}=0.3$.

with a row of very long yellowish setae; abdominal tergite VII (Fig. 3D) truncate at apex, with 2 pairs macrochaetae at middle and 3 pairs near apex; tergite VIII (Fig. 3E) slightly truncate at apex, with 1 pair of lateral macrochaetae and 2 pairs near apex; sternite VIII shaped as in Fig. 3F. Macrochaetotaxy of abdominal tergites II-VIII: 4, $2,4,4,4,10,6$.

Male. Median lobe of aedeagus shaped as in Fig. 3G-H.

Female. Unknown.

Measurements. BL: 1.51-1.61; FBL: 0.69-0.72; PL: 0.31-0.33; PW: 0.53-0.56; PW/PL: 1.66-1.74; HW/PW: 0.56-0.64. 
Distribution. Southwest China: Yunnan.

Symbiotic host. Dorylus orientalis Westwood, 1835.

Etymology. Named after Mr. Zhi-Gao Song, the senior author's father.

\section{Key to the species of Doryloxenus from China}

$1 \quad$ Forebody glabrous, with sparse and fine punctation...................................2

- $\quad$ Forebody sparsely covered with yellow setae .............................................5

2 Body broad; abdominal tergites and paratergites sparsely covered with setae ... 3

- $\quad$ Body slender; abdominal paratergites without setae. (Hongkong)

3 Posterior margin of elytra slightly concave ................................................ 4

- $\quad$ Posterior margin of elytra truncate. (Hongkong) ........... D. rougemonti Pace

4 Abdominal sternite VIII rounded at apex; aedeagus shaped as in Fig. 3G-H. (Yunnan)

D. songzhigaoi sp. $\mathrm{n}$.

- $\quad$ Abdominal sternite VIII slightly truncate at apex; aedeagal distal crest well developed, apical lobe curved ventrad at the middle. (Yunnan).

D. yunnanus Assing

Eyes generalized in size; elytra relatively long; hind wings. (Zhejiang)

D. tangliangi sp. $\mathbf{n}$.

- $\quad$ Eyes small; elytra short; hind wings reduced. (Zhejiang) ...D. aenictophilus sp. n.

\section{Acknowledgements}

We thank Mr. Weeyawat Jaitrong for sending reprints. We are especially grateful to Dr. Munetoshi Maruyama and Mr. Weeyawat Jaitrong for offering many helpful suggestions during this study. We thank Cong-Chao Dai, Jia-Yao Hu, Liang Tang and Zhong Peng (both Shanghai, China) for their support during the field work. Two anonymous reviewers critically read the manuscript and provided helpful advice. The study is supported by the National Natural Science Foundation of China (No. 31101659 and No. 31172134, 31201734) and Shanghai Normal University (DZL125).

\section{References}

Assing V (2009) New species and additional records of Homalotini, Athetini, Pygostenini, and Lomechusini from Yunnan, China (Coleoptera: Staphylinidae: Aleocharinae). Linzer biologische Beiträge 41(1): 485-507.

Jacobson HR (1980) Additional species and records from Africa of the myrmecophilous tribe Pygostenini (Coleoptera, Staphylinidae). Annales historic-naturales Musei natioalis hungarici 72: 133-138. 
Jacobson HR, Kistner DH (1975) A manual for the indication of the Pygostenini, the natural history of the myrmecophilous tribe Pygostenini. Sociobiology 1: 201-335.

Jaitrong W, Yamane S (2011) Synopsis of Aenictus species groups and revision of the A. currax and $A$. laeviceps groups in the eastern Oriental, Indo-Australian, and Australasian regions. Zootaxa 3128: 1-46.

Kistner DH, Berghoff SM, Maschwitz U (2003) Myrmecophilous Staphylinidae (Coleoptera) associated with Dorylus (Dichthadia) laevigatus (Hymenoptera: Formicidae) in Malaysia with studies of their behavior. Sociobiology 41(1): 209-266.

Naomi S (1996) Two new species of the tribe Pygostenini (Coleoptera, Staphylinidae, Aleocharinae) from Taiwan and Nepal. Entomological Review of Japan 51: 23-26.

Pace R (1998) Aleocharinae della Cina: Parte IV (Coleoptera, Staphylinidae). Revue Suisse de Zoologie 105: 911-982. 